
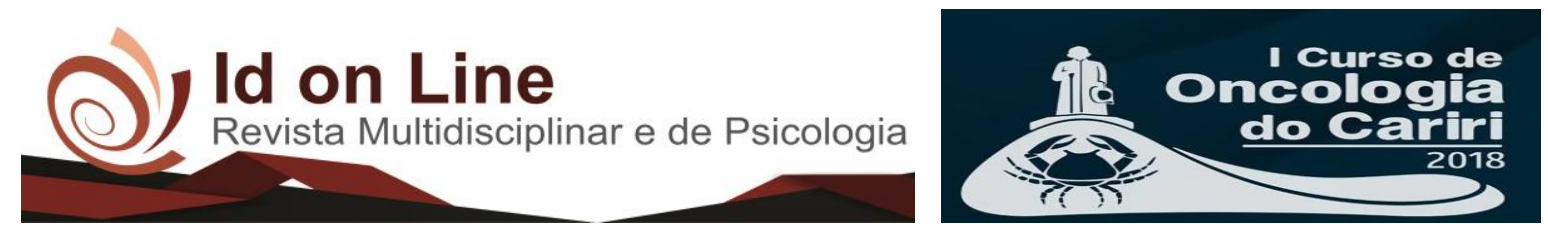

Resumo

\title{
LEUCEMIA MIELOIDE AGUDA (LMA) NA INFÂNCIA E ADOLESCÊNCIA: REVISÃO SISTEMÁTICA
}

\author{
Rivania Beatriz Novais Lima ${ }^{1}$, Antonio Marlos Duarte de Melol Amon Vitorino Duartel, \\ Esther de Macêdo Lira', Leyde Jenifer Dias Uchôa ${ }^{1}$, \\ Yara Talita Gomes Pereiral, Ricardo Souto Quidute ${ }^{2}$
}

Introdução: Leucemia é uma neoplasia maligna caracterizada por uma intensa substituição de células sanguíneas normais por células jovens imaturas, que impedem a formação das demais células na medula óssea, essenciais para o desenvolvimento e proteção do organismo. Este câncer apresenta grande capacidade de proliferação e com uma grande taxa de mortalidade. A incidência é alarmante em toda a população nacional, porém o grupo de maior incidência é a população pediátrica (até os 19 anos de idade). Objetivo: Identificar e analisar incidência nos últimos anos nessa faixa etária e constatar fatores etiológicos. Método: revisão sistemática de literatura de estudos primários e secundários, realizado no período de 2007 a 2017, nas seguintes bases de dados: PubMed, Scielo e LILACS. Utilizou-se os descritores: "leukema", "incidence", além da palavra-chave "Câncer", combinados com operador booleano "and", conforme a seguinte equação de busca: leukema and incidence and câncer. Resultados: A partir de oito artigos selecionados, as taxas de incidência por Leucemia Mieloide Aguda apresentam tendência de crescimento, enquanto no subgrupo denominado "Outros tipos de leucemias", observa-se tendência de queda. De forma sumária, a mortalidade por leucemias tende a aumentar para meninos e meninas, principalmente nas faixas etárias de 10 a 14 anos (aumento percentual anual de $1,23 \%$ para meninos e $1,28 \%$ para meninas) e 15 a 19 anos (aumento percentual anual de 1,40\% para meninos e 1,62\% para meninas), dados de 1980 até 2010. Quanto ao aspecto etiológico, foi encontrado que 76,3\% dos pacientes em pesquisas, apresentam alteração citogenéticas. Conclusão: As leucemias compreendem o grupo mais frequente de neoplasias em crianças e adolescentes. Há um crescimento da incidência de LMA nos últimos anos, e entre pacientes submetidos estudos, mais de 50\% apresentam alteração genética.

Palavras-chave: Leucemia. Neoplasia.

\footnotetext{
1. Acadêmico do curso de Medicina da Faculdade de Medicina Estácio de Juazeiro do Norte (Estácio-FMJ).

${ }^{2}$. Professor, Estácio-FMJ, Juazeiro do Norte-CE. Médico pela Faculdade de Ciências Médicas de Pernambuco. Diretor clínico no Instituto de mama. Orientador da LAON (liga de oncologia).

Autor correspondente: rivania.bnovais@gmail.com.
}

44 Id on Line Rev. Mult. Psic. V.12, N. 40. 2018 - ISSN 1981-1179 EDIÇÃO ESPECIAL: I CURSO DE ONCOLOGIA DO CARIRI / II JORNADA DE PESQUISA QUANTI-QUALITATIVA EM ONCSOLOGIA. JUAZEIRO DO NORTE, 05 A 10 DE MARÇO DE 2018. Edição eletrônica em http://idonline.emnuvens.com.br/id 